\title{
Empowering UMKM Dengan Pemanfaatan Digital Marketing Di Era New Normal (Literasi Media Digital Melalui Webinar)
}

\author{
Mira Veranita 1, Ramayani Yusuf ${ }^{2, *}$, Yuda Syahidin ${ }^{3}$, Rini Susilowati ${ }^{1}$, Dian Candra \\ Fatihah $^{2}$, Wiwi Warsiati ${ }^{2}$ \\ 1 Program Studi Manajemen Bisnis; Politeknik Piksi Ganesha; Jalan Gatot Soebroto 301 \\ Bandung; telp: (022) 87340030; e-mail: mirave2198@gmail.com, rinisusilo.ppg@gmail.com \\ 2 Program Studi Administrasi Keuangan; Politeknik Piksi Ganesha; Jalan Gatot Soebroto 301 \\ Bandung; telp: (022) 87340030; e-mail: yusuframayani@gmail.com, \\ diancandrafatihah@gmail.com, wiwiwarsiati@gmail.com \\ ${ }^{3}$ Program Studi Manajemen Informatika; Politeknik Piksi Ganesha; Jalan Gatot Soebroto 301 \\ Bandung; telp: (022) 87340030; e-mail: yudasy@gmail.com \\ * Korespondensi: e-mail: yusuframayani@gmail.com
}

\begin{abstract}
There are many problems faced by MSMEs due to the Covid-19 pandemic, even though MSMEs have a large enough contribution to national economic growth. Even though several types of businesses have actually experienced development, in general, MSMEs have been greatly affected. MSMEs must be able to adapt to the changes that occur, between innovating and utilizing digital marketing in running their business, especially in marketing their products. To support the digitization of MSMEs so that they are able to adapt to these changes, community service activities are carried out. This digital literacy is in a webinar format using the Zoom Meeting and Youtube Streaming application, which was attended by 147 participants, MSME owners, observers and academics from various cities in Indonesia. Activities run smoothly, with materials delivered by academics and practitioners in their fields. The participants were quite enthusiastic because the delivery was clear and interesting, so that the feedback obtained was quite satisfying, although there were still a few shortcomings.
\end{abstract}

Keywords: Branding, Digital Marketing, Literacy, MSMEs

\begin{abstract}
Abstrak
Banyak permasalahan yang dihadapi UMKM akibat pandemi Covid-19, padahal UMKM memiliki kontribusi yang cukup besar terhadap pertumbuhan ekonomi nasional. Meskipun beberapa jenis usaha benar-benar mengalami perkembangan, namun secara umum UMKM sangat terpengaruh. UMKM harus mampu beradaptasi dengan perubahan yang terjadi, antara berinovasi dan memanfaatkan digital marketing dalam menjalankan usahanya, khususnya dalam memasarkan produknya. Untuk mendukung digitalisasi UMKM agar mampu beradaptasi dengan perubahan tersebut maka dilakukan kegiatan pengabdian kepada masyarakat. Literasi digital ini dalam format webinar dengan menggunakan aplikasi Zoom Meeting dan Youtube Streaming yang diikuti oleh 147 peserta, pemilik UMKM, pemerhati dan akademisi dari berbagai kota di Indonesia. Kegiatan berjalan dengan lancar, dengan materi yang disampaikan oleh akademisi dan praktisi dibidangnya. Peserta cukup antusias karena penyampaiannya jelas dan menarik, sehingga feedback yang didapat cukup memuaskan walaupun masih ada beberapa kekurangan.
\end{abstract}

Kata kunci: Brand, Digital Marketing, Literasi, UMKM 


\section{Pendahuluan}

Transformasi di dunia bisnis, termasuk UMKM tidak bisa dihindari akibat merebaknya Pandemi Covid-19. Tidak sedikit UMKM yang terimbas karena kondisi ini, mulai dari merosotnya omzet hingga masalah-masalah yang terkait dengan kerjasama dengan mitra-mitra UMKM (Marlinah, 2020) (Rosita, 2020). Pandemi Covid-19 telah menghadirkan berbagai tantangan bagi pelaku UMKM, antara lain dengan menurunnya daya beli masyarakat akibat adanya kebijakan pembatasan interaksi secara langsung.

Berdasarkan data kementrian Koperasi UKM, dari jumlah usaha mikro sebanyak 62.106.900, usaha kecil sebanyak 757.090, usaha menengah sebanyak 58.627 dan usaha besar sebanyak 5.460 unit, hampeir $98 \%$ dari total UMKM itu terdampak pandemi. Sebelum pandemi terjadi, UMKM menyumbang sangat besar terhadap pertumbuhan ekonomi nasional. (Veranita, 2019) Ekonomi Indonesia hampir 80\% ditopang oleh konsumsi dalam negeri dan UMKM berkontribusi terhadap produk domestik bruto (PDB) Indonesia mencapai $65 \%$ atau sekitar 2.394,5 triliun (Hardilawati, 2020).

Banyak hal terjadi dan berubah saat pandemi melanda. Memang ada beberapa jenis bisnis UMKM yang justru melesat saat pandemi, namun sebagian besar terpuruk dan bermasalah, terutama di kurun awal 2020 hingga akhir 2020. Berbagai perubahan yang terjadi antara lain mode komunikasi, pola kerja hingga dinamika tim internal, begitupun pola perilaku konsumen mengharuskan para pelaku UMKM juga bisa merespon dengan cepat dan tanggap. Bermacam cara dilakukan oleh para pelaku UMKM untuk tetap bertahan, bertumbuh dan berkembang. Pergeseran pola pemasaran produk UMKM dari offline ke online nampaknya memaksa UMKM untuk dapat mengikuti perubahan tersebut. Saat ini, berdasarkan data Kementrian UKM baru sekitar 8 juta UMKM atau 13\% dari seluruh UMKM yang mampu memanfaatkan teknologi informasi dalam bisnisnya. Padahal setelah memasuki era new normal ini, banyak sektor harus tetap bisa berjalan dengan mengikuti anjuran protokol kesehatan, dan UMKM harus menyiapkan beberapa hal, antara lain menjadikan inovasi sebagai kunci untuk beradaptasi (ES et al., 2017). Inovasi yang utama adalah improvisasi dari penjualan offline yang diintegrasikan dengan penjualan online, sehingga adopsi digital menjadi hal yang sangat penting, selain melakukan inovasi-inovasi perubahan. (Laluyan, 2019)(Wardhana, 2015). Saat ini E-Commerce bukan lagi hanya sebatas wadah berjualan atau berniaga bagi UMKM, namun juga termasuk di dalamnya kemampuan memperkenalkan dan mempromosikan produk, melakukan pengembangan kualitas produk dan kemasan, bahkan peningkatan metode pembayaran dan pembelian.

Saat ini berbinsis dengan memanfaatkan e-commerce dan digital marketing juga menjadi kebutuhan utama konsumen dalam bertransaksi di masa pandemi ini sehingga pembelian secara online melalui beberapa platform e-commerce menuntut UMKM bisa beradaptasi dengan hal tersebut (Sudaryono et al., 2020). Beberapa permasalahan yang dihadapi oleh UMKM untuk melakukan perubahan antara lain adalah kurangnya pengetahuan dan kemampuan UMKM dalam memanfaatkan teknologi digital untuk memasarkan produknya 
maupun untuk kegiatan-kegiatan lain, (Oktaviani, 2018) padahal tingkat kepemilikan smartphone dan penetrasi internet saat ini sangat tinggi, terutama di masa pandemi ini. Selain itu rendahnya tingkat literasi digital, literasi keuangan dan literasi keuangan digital juga menjadi masalah yang dihadapi UMKM dalam beradaptasi di era new normal saat ini. Dalam rangka mendukung digitasi UMKM agar mampu beradaptasi dengan perubahan yang terjadi saat ini dan mampu meningkatkan akses terhadap berbagai layanan sehingga membantu UMKM bertahan dan bertumbuh saat ini, maka dilaksanakanlah kegiatan pengabdian pada masyarakat, yaitu berupa Webinar dengan tema "Empowering UMKM dengan Pemanfaatan Digital marketing di Era New Normal"

\section{Metode Pelaksanaan}

Pengabdian pada Masyarakat adalah hasil kerjasama Komite Ekraf Kabupaten Bandung, Dikhumsaintek UPI dan Kabupaten Bandung Creative Hub, dengan tujuan memberikan wawasan dan pengetahuan kepada UMKM untuk menggunakan teknologi informasi dan telekomunikasi untuk menjalankan aktivitas bisnis mereka, sehingga mampu beradaptasi dengan pergerakan dan perubahan cara berbisnis yang saat ini bergerak cukup pesat. Setelah kegiatan ini diharapkan peserta terdorong dan termotivasi untuk mulai memanfaatkan teknologi digital dalam menjalankan bisnisnya.

Kegiatan Pengabdian kepada Masyarakat ini dilakukan dalam bentuk Webinar melalui aplikasi Zoom Meeting dan Streaming YouTube. Pemberian materi dilakukan dengan menggunakan metode presentasi dari para pemateri. Metode ceramah/presentasi dilanjutkan dengan metode Tanya jawab antara peserta dengan pemateri, untuk membantu memecahkan permasalahan yang dihadapi pelaku UMKM dan juga sebagai tolak ukur penyampaian materi yang disampaikan oleh pemateri.

\section{Hasil dan Pembahasan}

Kegiatan ini dilaksanakan pada hari Rabu, 29 April 2021, dengan menggunakan Ruangan Virtual Zoom Meeting melalui link address yang sudah dipublikasikan sebelumnya, memalui media Whatsapp Group, Telegram Group dan e-mail masing-masing peserta. Yaitu https://us02web.zoom.us/j/88159133113?pwd=eWYzcmdZbXF1aXF1MWNKZW9oUmRTUT09.

Peserta yang mendaftar melalui Google Form yang sudah diedarkan oleh tim adalah 184 orang, namun yang menghadiri acara sejak pembukaan hingga kegiatan selesai adalah sejumlah 147 orang, yang berasal dari beberapa kota di Indonesia, seperti Banda Aceh, Riau, lampung, Kalimantan, Surabaya, malang, Bandung, Jakarta dan beberapa kota lain, dengan gambaran peserta yang dapat dilihat pada grafik berikut. 


\section{Peserta Webinar}

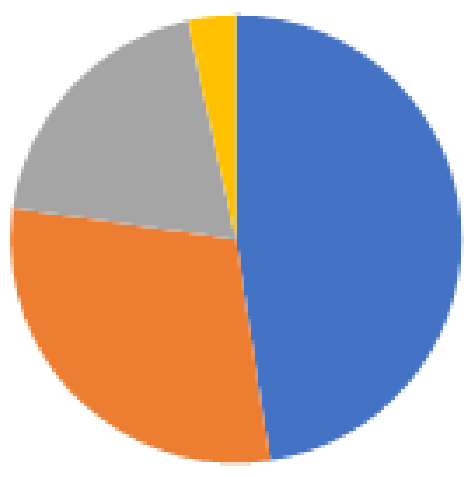

- Pelaku UMKM

- Pemerhati UMKM

Mahasiswa/Akademisi

Lain-lain

Sumber: Hasil Pelaksanaan (2021)

Gambar 1. Gambaran Peserta Webinar

Metode ceramah (Presentasi) yang disampaikan oleh Pemateri dilengkapi dengan penayangan slide Power Point dan beberapa video sehingga membuat materi tersampaikan dengan cepat dan padat namun mudah dipahami.

Selama berlangsungnya kegiatan, peserta nampak tertarik dan antusias, hal ini bisa dilihat dari partisipasi peserta ketika diminta memberikan jawaban dan pernyataan saat Pemateri melibatkan peserta secara interaktif. Antusias peserta juga ditunjukkan dengan banyaknya pertanyaan mengenai materi yang disampaikan.

Materi-materi yang disampaikan selain mengacu pada literatur ilmiah dan teori-teori yang relevan karena Pemateri 1 adalah akademisi, juga bersumber dari pengetahuan dan pengalaman bisnis di lapangan, karena Pemateri 2 adalah praktisi dan Pembina UMKM yang memiliki kompetensi tinggi sehingga topik yang disampaikan sesuai dengan tema yang telah direncanakan. Susunan acara pelaksanaan webinar disajikan pada tabel 1.

Tabel 1. Susunan Acara Webinar

\begin{tabular}{|c|c|c|}
\hline WAKTU & KEGIATAN & PELAKSANA \\
\hline $09.30-10.00$ & Conditioning & Seluruh Tim \\
\hline $10.00-10.15$ & $\begin{array}{l}\text { Sambutan, Pembacaan Doa, Sesi Foto } \\
\text { Bersama, Pemutaran Video Profil } \\
\text { Pelaksana dan Pendukung Acara }\end{array}$ & $\begin{array}{l}\text { Pembawa Acara, Dian Candra } \\
\text { Fatiha., SP., MM }\end{array}$ \\
\hline $10.15-10.30$ & Sambutan, Keynote Speaker & $\begin{array}{l}\text { Wahyu Frayudha (Ketua Komisi } \\
\text { Ekonomi Kreatif Kabupaten } \\
\text { Bandung) }\end{array}$ \\
\hline $10.30-10.35$ & Perkenalan dengan Pemateri 1 & $\begin{array}{l}\text { Moderator: Ramayani Yusuf., S.Sos., } \\
\text { MM }\end{array}$ \\
\hline $10.35-10.55$ & Materi 1: Pemanfaatan Digital Marketing & Dr. Heny Hendrayati., MM \\
\hline
\end{tabular}




\begin{tabular}{cll}
\hline WAKTU & \multicolumn{1}{c}{ KEGIATAN } & \multicolumn{1}{c}{ PELAKSANA } \\
\hline $10.55-11.00$ & Perkanalan dengan Pemateri 2 & $\begin{array}{l}\text { Moderator: Ramayani Yusuf., } \\
\text { S.Sos.,MM }\end{array}$ \\
\hline $11.00-11.20$ & Materi 2: UMKM Go Digital & Rini Susilowati., S.Ip.,M.MPd \\
\hline $11.20-12.00$ & Sesi Tanya Jawab, Pembagian Door Prize & Ramayani Yusuf., S.Sos.,MM \\
& dan hadiah dari Sponsor & \\
\hline $12.00-12.10$ & Doa, Penutup & Pembawa Acara, Dian Candra \\
& & Fatiha., SP., MM \\
\hline
\end{tabular}

Sumber: Hasil Pelaksanaan (2021)

Wahyu Frayudha atau dikalangan para pelaku UMKM biasa dikenal Kang Rakha, saat ini selain menjabat sebagai Ketua Komite Ekonomi Kreatif Kabupaten Bandung, juga menjadi pimpinan di Yayasan Klinik Media Kreatif dan Badan Usaha Milik Desa (BUMD). Dalam pemaparannya beliau menyampaikan judul "Memberdayakan UMKM dengan Pemanfaatan Digital marketing di Era New Normal". Penjelasan yang cukup menggelitik bagi UMKM mengenai bagaimana sebaiknya memulai sebuah usaha. Lebih lanjut pemaparannya menjelaskan mengenai perbedaan fungsi Marketing, Selling dan Branding, dan memberikan cara mudah membuat branding yang meliputi Strategy, Inventory Brand dan Activasi Brand.

Dr. Heny Hendrayati., MM, seorang Dosen dan Peneliti di Fakultas Ekonomi Bisnis Universitas Pendidikan Indonesia yang memiliki ketertarikan pada organisasi nirlaba, penelitian kewirausahaan terutama terkait UMKM dan Womenpreneur, memiliki kemampuan analis, negosiasi dan praktisi bisnis, menyampaikan materi dengan tema "Pemanfaatan Digital Marketing". Dalam pemaparannya disampaikan pemahaman mengenai branding, dan dijelaskan bahwa branding diperlukan bukan hanya untuk usaha-usaha besar namun termasuk juga Usaha-usaha mikro, kecil dan menengah.

Lebih lanjut dijelaskan Strategi dan aspek-aspek penting dalam branding, yang meliputi jenis konten apa yang akan di share, gaya dan tema desain yang khas, bagaimana suatu konten bisa memberikan manfaat dan menciptakan persepsi kelompok dan membangun komunitas dan hal yang tidak kalah pentingnya adalah bagaimana membangun konsistensi postingan (konten).

Pemaparannya cukup menarik atensi peserta terutama ketika memasuki materi bagaimana UMKM bisa memanfaatkan digital marketing dengan menggunakan sosial media, content marketing, email marketing dan search engine marketing. Tidak bisa dipungkiri, meskipun saat ini hampir semua peserta webinar sudah memiliki device untuk berinteraksi secara digital (mobile phone/ laptop) namun penggunaannya masih sangat terbatas untuk berkomunikasi. Pemanfaatan aplikasi-aplikasi, software dan fitur-fitur yang mendukung pembuatan konten sebagai media promosi dan berjualan masih sangat kurang dikuasai. Media sosial yang mereka gunakan masih terbatas untuk bersosialisasi dan berinteraksi padahal kalau dimanfaatkan dengan baik bisa menjadi alat untuk meningkatkan pemasaran dan penjualan. 
Untuk itu, nampaknya perlu di kemudian hari dilakukan pelatihan untuk membuat konten promosi (baik dalam bentuk foto, e-brosur maupun video) juga pelatihan fotografi bagi para pelaku UMKM dengan menggunakan sarana sederhana.

Di akhir penjelasannya dipaparkan tips dan trik praktis bagi pelaku UMKM mengenai bagaimana membuat konten marketing yang menarik dan efektif untuk pemasaran melalui pembuatan article, infographic, video, PDF (magazine/EBook), dan memanfaatkan SEO pada search engine.

Rini Susilowati., S.IP.,MM adalah dosen di Politeknik Piksi Ganesha yang saat ini juga menjabat sebagai Direktur Pengembangan Program Pelatihan SMESCO Institute, Dewan Pengawas Koperasi Raharja Indriyaloka, Konsultan BAPPEDA untuk Tim Ekonomi, Asesor UMKM, Asesor MSDM dan sampai saat ini sebagai Sekjen Komite Ekraf Kabupaten Bandung yang memiliki atensi cukup besar terhadap Pengembangan UMKM di Kabupaten Bandung khususnya, dan di Jawa Barat pada umumnya.

Materi yang disampaikan bertemakan UMKM Go Digital, yang menjelaskan mengenai Kondisi Transformasi perdagangan saat ini, pentingnya UMKM Go Digital, Tips dan Trik Marketing bagi UMKM di Era New Normal dan Tranformasi Digitalisasi UMKM.

Dijelaskan bahwa saat ini dalam kehidupan masyarakat penggabungan pasar dan usaha konvensional melalui media sosial sampai ke layanan e-commerce sudah semakin berbaur, sehingga UMKM haruslah mulai menyesuaikan diri juga bertransformasi dalam operasional bisnisnya. Berbagai hal untuk mendukung transformasi digital UMKM telah dipersiapkan oleh pemerintah baik itu berupa anggaran stimulus dari sisi penawaran bahkan juga restrukturisasi pinjaman, subsidi bunga, subsidi pajak dan lainnya, termasuk penyerapan produk-produk local. Diharapkan UMKM bisa lebih gesit bertindak dan mengasah skill dan pengetahuannya dalam menggunakan berbagai platform yang mensupport bisnis UMKM.

Pemaparannya sangat bersemangat dan lugas, sehingga menarik perhatian peserta karena juga berisi motivasi dan tips\& trik yang menyemangati dan mempermudah UMKM untuk Go Digital.

Sesi tanya jawab dilaksanakan setelah pemaparan materi. Antusiasme peserta dapat terlihat dari pertanyaan-pertanyaan yang diberikan. Pertanyaan-pertanyaan yang muncul cukup banyak, namun pada tabel berikut ini akan disampaikan beberapa pertanyaan yang disampaikan secara langsung maupun melalui chat room.

Tabel 2. Penanya dan Pertanyaan

\begin{tabular}{ll}
\hline PENANYA & PERTANYAAN \\
\hline Kasino M & Apakah perbedaan product value dan brand? \\
\hline Didi Susianto & Bagaimana caranya membuat brand yang jujur? \\
\hline Drajat Sulistyono & Untuk memulai suatu usaha, modal merupakan hal yang penting, karena \\
& pengusaha yang berhasil bukan hanya yang dicetak oleh orang kaya dan \\
& semua butuh modal. Bagaimanakah dengan hal tersebut? \\
\hline Jon Hendra & Bagaimana cara menumbuhkan kepercayaan diri dengan branding produk \\
\hline
\end{tabular}




\begin{tabular}{ll}
\hline PENANYA & PERTANYAAN \\
& kita? Apa saja tips dan triknya? \\
\hline Euis Hernawati & Mana yang harus didahulukan ketika kita membuat usaha, membangun \\
& branding atau membuat legalitas terlebih dahulu? \\
\hline Gunardi & Bagaimana cara yang baik dan benar dalam mengelola personal branding? \\
& Kebetulan saya bisnis konsultan dari produk-produk vitamin. \\
\hline Iryani & Apakah kendala nyata terbesar yang biasa dihadapi oleh UMKM di era \\
& digital ini?
\end{tabular}

Sumber: Hasil Pelaksanaan (2021)

Setelah pembahasan materi-materi dan diskusi mengenai tanya jawab di atas, peserta diminta untuk mengisi link Daftar hadir yang di dalamnya berisi angket (isian) untuk mengetahui feedback peserta berupa kesan, masukan, saran maupun kritik terhadap jalannya webinar, melalui link https://bit.ly/2QCZDja.

Nantinya feedback dari peserta akan dijadikan sebagai masukan perbaikan seminar dan pelatihan pada masa yang akan datang. Beberapa saran dan masukan dari peserta disajikan dalam tabel 3.

Tabel 3. Testimoni dan Masukan

\begin{tabular}{|c|c|}
\hline TESTIMONI & MASUKAN \\
\hline $\begin{array}{l}\text { Terimakasih atas materi yang telah } \\
\text { disampaikan, materi disampaikan dengan } \\
\text { sangat menarik sehingga dapat menyimak } \\
\text { webinar dengan baik }\end{array}$ & $\begin{array}{l}\text { Sudah sangat baik, sehingga diharapkan kedepannya } \\
\text { akan ada webinar seperti ini lagi }\end{array}$ \\
\hline $\begin{array}{l}\text { Pembawaan materinya cukup jelas, namun } \\
\text { seperti dikejar dedline (terlalu cepat) }\end{array}$ & $\begin{array}{l}\text { Memang seni, supaya materi terbagi baik, serta ruang } \\
\text { tanya jawab yg baik pula, namun di seminar atau } \\
\text { pelatihan yang akan datang bisa lebih diperlambat. }\end{array}$ \\
\hline Materi keren...marketing banget & $\begin{array}{l}\text { Maaf audio agak kurang jelas, lain kali dipersiapkan } \\
\text { dengan baik }\end{array}$ \\
\hline $\begin{array}{l}\text { Saya suka dengan penyampaian materinya } \\
\text { sangat detail. }\end{array}$ & $\begin{array}{l}\text { webinarnya sangat bagus dan memberikan banyak } \\
\text { pelajaran untuk para pelaku umkm yang mau go digital }\end{array}$ \\
\hline $\begin{array}{l}\text { Luar biasa, saya jadi mengerti tentang } \\
\text { branding yang memang ternyata sangat } \\
\text { berpengaruh untuk produk kita }\end{array}$ & Tolong adakan seminar tentang HKI \\
\hline Kompeten dan bermanfaat & $\begin{array}{l}\text { Awesome. Narasumber nya bagus, meskipun waktu } \\
\text { singkat tapi materinya bisa di perjelasin dengan baik. }\end{array}$ \\
\hline Menginspirasi & $\begin{array}{l}\text { Bagus sekali dan semoga materi yang disampaikan bisa } \\
\text { di praktekkan dalam bisnis yang kita bangun suatu saat } \\
\text { nanti. }\end{array}$ \\
\hline $\begin{array}{l}\text { Sangat menarik dan gaya bahasanya cocok } \\
\text { untuk milineal...senang sekali :) }\end{array}$ & Waktu untuk masing2 pemateri terlalu sedikit \\
\hline $\begin{array}{l}\text { Materi yang di sampaikan sangat menarik } \\
\text { karena contoh yang di gunakan brand }\end{array}$ & $\begin{array}{l}\text { Bagus, tapi waktu yang di berikan untuk para pemateri } \\
\text { menurut saya kurang. }\end{array}$ \\
\hline
\end{tabular}




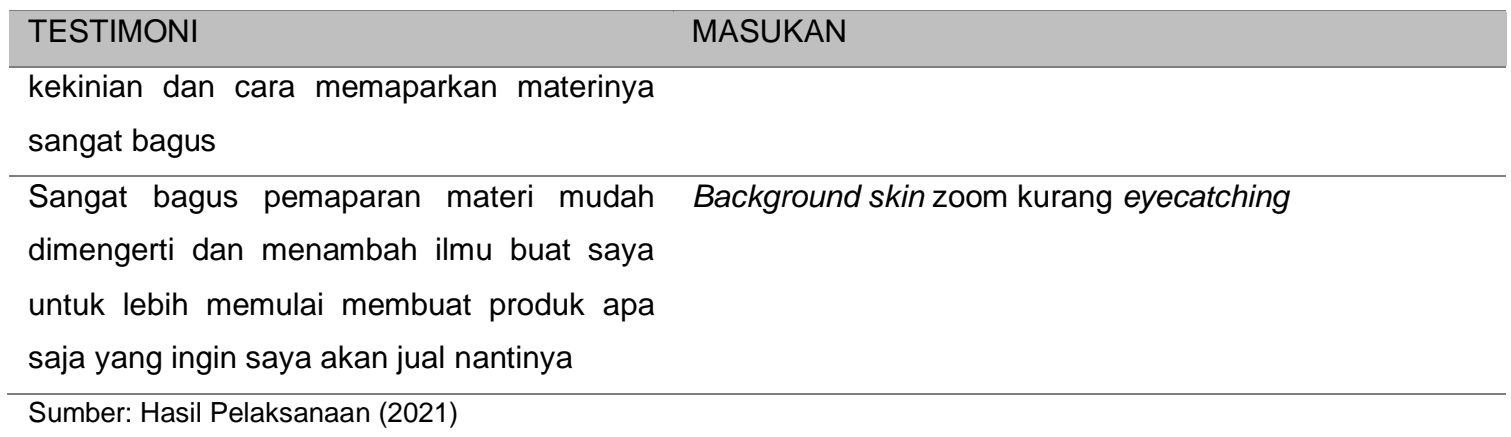

Beberapa saran dan masukan dari peserta akan diperhatikan demi perbaikan di masa yang akan datang. Berikut adalah foto-foto selama kegiatan penyampaian materi dari kegiatan pengabdian kepada masyarakat yang telah dilakukan.

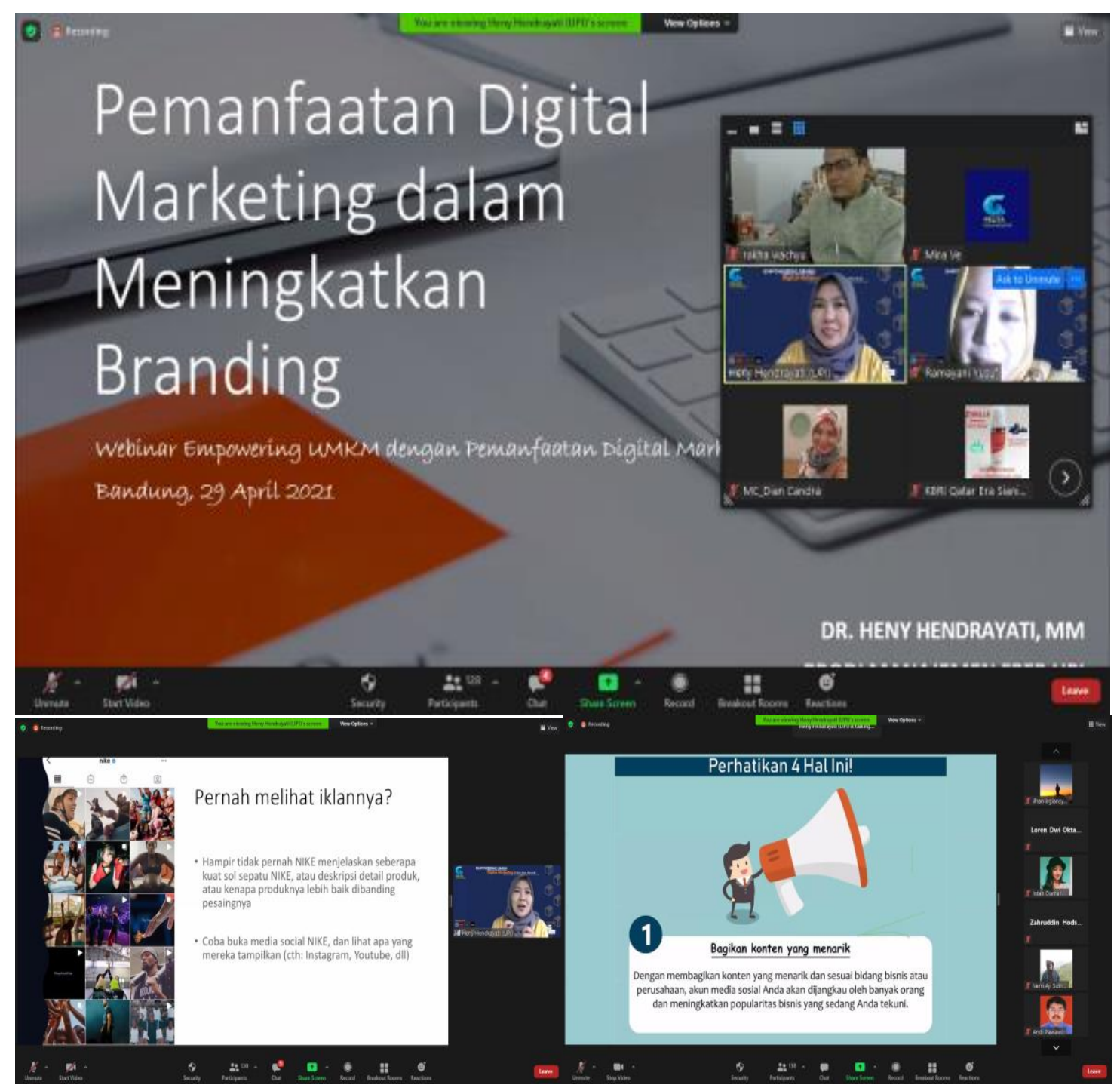

Sumber: Hasil Pelaksanaan (2021)

Gambar 2. Materi Kegiatan Webinar

Setelah materi disampaikan oleh para pemateri maka sesi selanjutnya adalah sesi tanya jawab. Pada sesi ini nampak antusiasnya peserta dengan kegiatan ini, hal ini ditunjukkan 
dengan banyaknya peserta yang bertanya dan merasa tertarik untuk informasi yang lebih dari kegiatan ini.

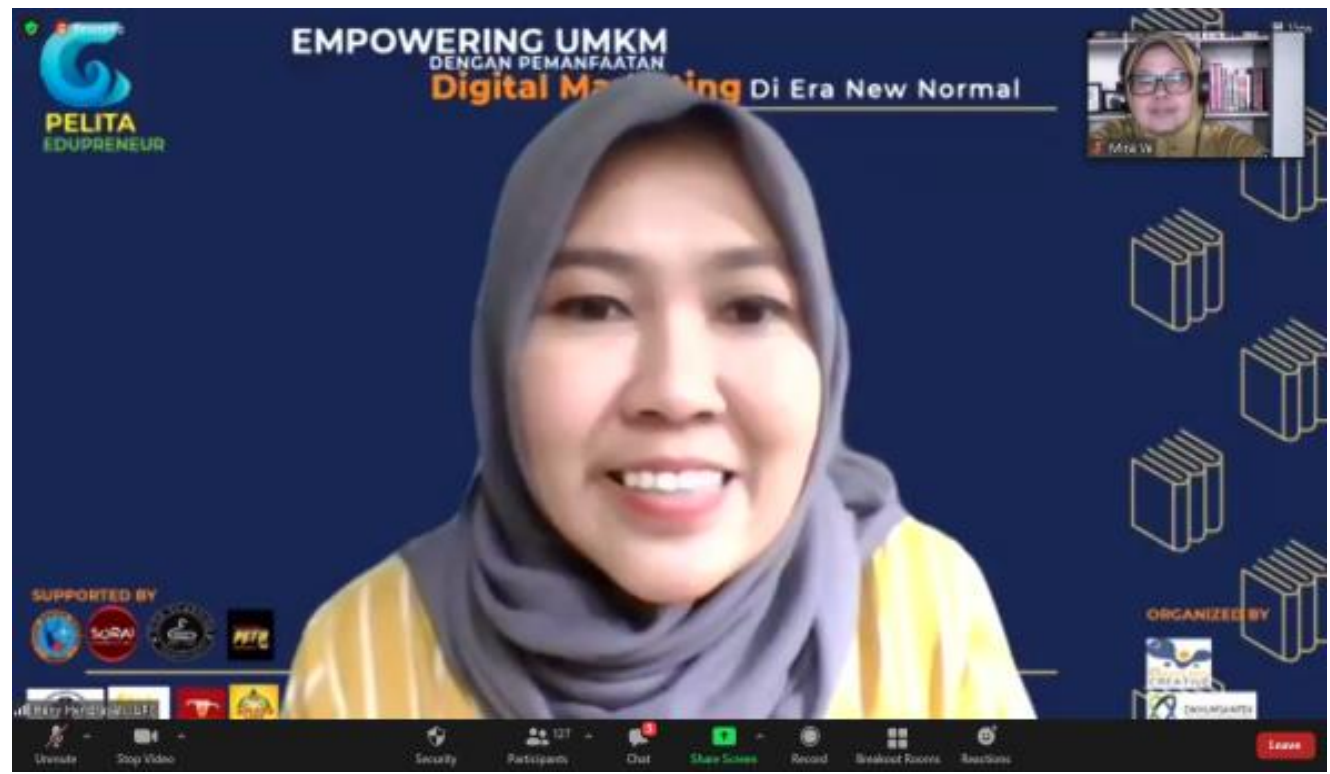

Sumber: Hasil Pelaksanaan (2021)

\section{Gambar 3. Sesi Tanya Jawab}

Berikut dokumentasi dari kegiatan foto bersama anatar panitian dengan pihak peserta kegiatan pengabdian kepada masyarakat yang dilakukan secara daring.
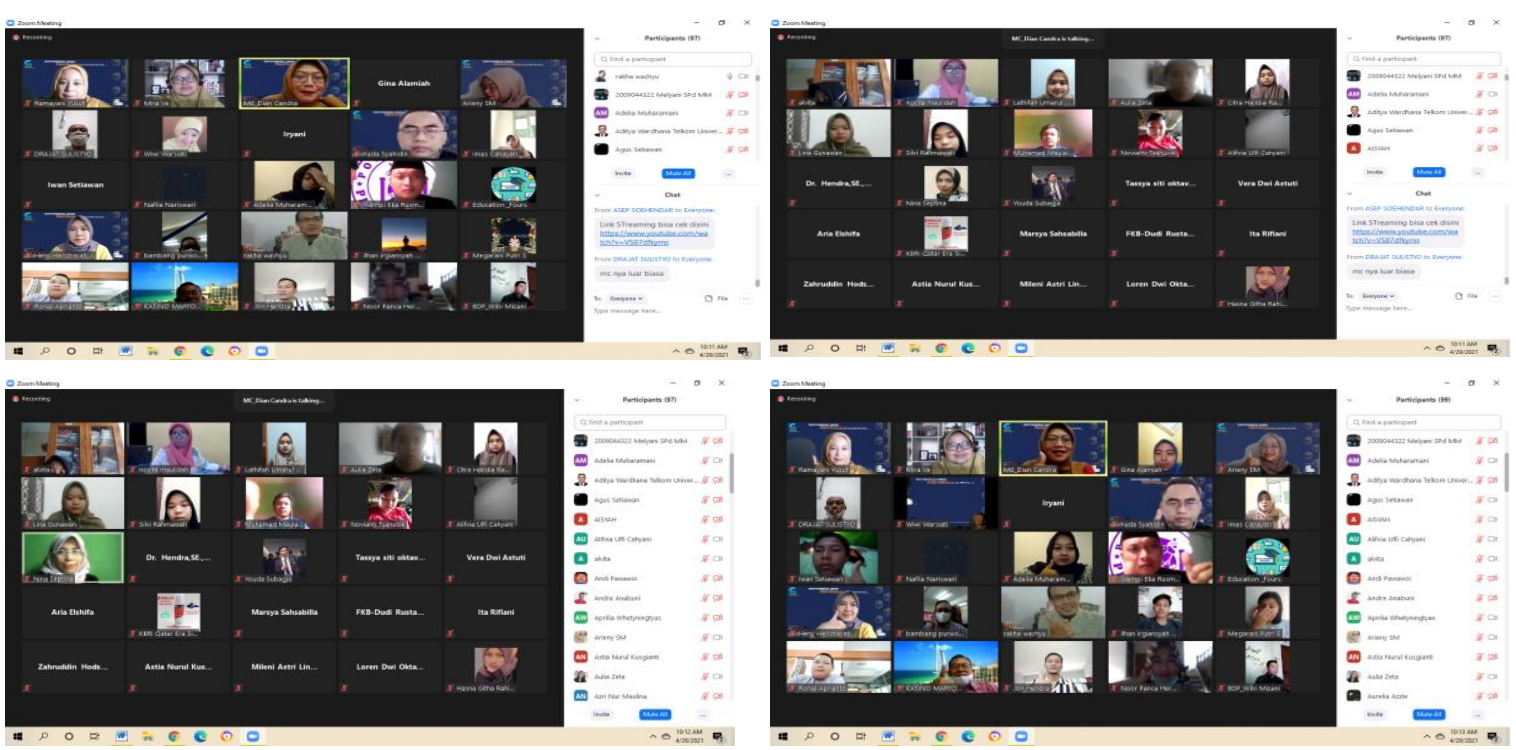

Sumber: Hasil Pelaksanaan (2021)

Gambar 4. Sesi Foto Bersama

\section{Kesimpulan}

Secara umum, kegiatan Pengabdian kepada Masyarakat dalam bentuk Webinar mengenai "Empowering UMKM dengan Pemanfaatan Digital Marketing di Era New Normal" telah berlangsung dengan baik, lancar dan tanpa kendala-kendala yang berarti. Peserta nampak cukup antusias, kooperatif dan mendukung, hal ini dapat dilihat dari kondisi kehadiran 
dan partisipasi peserta yang relatif stabil sejak awal hingga akhir kegiatan. Hasil dari kegiatan ini adalah menambah informasi, wawasan dan motivasi para pelaku UMKM untuk mulai memanfaatkan teknologi digital dalam mempertahankan pelanggan dan memajukan bisnisnya. Kegiatan ini mampu menarik perhatian para pelaku UMKM, Akademisi, mahasiswa dan masyarakat pemerhati UMKM untuk meningkatkan pengetahuan dan kemampuannya sehingga UMKM Go Digital akan lebih cepat terwujud. Segala kritik, saran dan masukan akan digunakan sebagai alat untuk memperbaiki kegiatan di masa yang akan datang agar bisa lebih baik lagi.

\section{Ucapan Terima Kasih}

Terima kasih kepada para sponsor Bale Suung, PHRI Kabupaten Bandung, Ekraf Kabupaten Bandung, LPPM Universitas Pendidikan Indonesia, Pelita Edupreuner, Kopi Mage, Rida Fashion, Baso Petir, KolakuLaku, Sorai, atas kerjasamanya.

\section{Daftar Pustaka}

ES, D. P., Rahmi, \& Shandy, A. (2017). Pemanfaatan Digital Marketing bagi Usaha Mikro, Kecil dan Menengah (UMKM) di Kelurahan Malaka Sari, Duren Sawit. Jurnal Pemberdayaan Masyarakat Madani (JPMM), 1(1), 1-17.

Hardilawati, W. laura. (2020). Strategi Bertahan UMKM di Tengah Pandemi Covid-19. Jurnal Akuntansi Dan Ekonomika, 10(1), 89-98. https://doi.org/10.37859/jae.v10i1.1934

Herlawati, Handayanto, R. T., \& Solikin. (2018). Neural network regression with support vector regression for land-use growth prediction. Proceedings of the 3rd International Conference on Informatics and Computing, ICIC 2018. https://doi.org/10.1109/IAC.2018.8780475

Laluyan, G. I. (2019). Implementasi Digital Marketing terhadap Keputusan Pembelian Konsumen. Jurnal Manajemen Bisnis Krisnadwipayana, 7(3).

Marlinah, L. (2020). Peluang dan Tantangan UMKM Dalam Upaya Memperkuat Perekonomian Nasional Tahun 2020 Ditengah Pandemi Covid 19. Jurnal Ekonomi, 22(2), 118-124.

Oktaviani, F. (2018). Implementasi Digital Marketing dalam Membangun Brand Awareness. PRofesi Humas, 3(1), 1-20.

Pratiwi, E. S., \& Herlawati, H. (2019). Sistem Informasi Penjualan Katering Berbasis Web Pada CV. Saung Alit Telaga Murni Cikarang Barat Eka. Information System For Educators And Professionals, 03(2), 177-188.

Rosita, R. (2020). Pengaruh Pandemi Covid-19 Terhadap Umkm Di Indonesia. Jurnal Lentera Bisnis, 9(2), 109. https://doi.org/10.34127/jrlab.v9i2.380

Sudaryono, Rahwanto, E., \& Komala, R. (2020). E-commerce dorong perekonomian Indonesia, selama pandemi covid 19 sebagai entrepreneur. Jurnal Manajemen Dan Bisnis (Jumanis) Prodi Kewirausahaan, 2(3), 200-213.

Wardhana, A. (2015). Strategi Digital Marketing dan Implikasinya Pada Keunggulan Bersaing UMK di Indonesia. In Seminar Nasional Keuangan Dan Bisnis IV, April 2015, 327-337. 